\title{
Oxidation Induced Polymerization of InP Surface and Implications for Optoelectronic Applications
}

\author{
Xueqiang Zhang, ${ }^{1,2+*}$ Tadashi Ogitsu, ${ }^{3+^{* *}}$ Brandon C. Wood, ${ }^{3 *}$ Tuan Anh Pham, ${ }^{3}$ and Sylwia Ptasinska ${ }^{1,4}$ \\ ${ }^{1}$ Radiation Laboratory, University of Notre Dame, Notre Dame, IN 46556, USA; \\ ${ }^{2}$ Department of Chemistry and Biochemistry, University of Notre Dame, IN 46556, USA; \\ ${ }^{3}$ Quantum Simulations Group, Lawrence Livermore National Laboratory, Livermore, CA 94550, USA; \\ ${ }^{4}$ Department of Physics, University of Notre Dame, Notre Dame, IN 46556, USA.
}

\section{Corresponding Author}

*E-mail: xzhang10@alumni.nd.edu; ogitsu1 @1lnl.gov; wood37@1lnl.gov;

${ }^{\dagger}$ These authors contributed equally.

${ }^{+}$Current address: 1 Cyclotron Rd., Chemical Science Division, Lawrence Berkeley National Laboratory, Berkeley, CA 94820, USA 
Supporting information

\section{Surface pretreatment}

An InP(001) wafer (undoped) was purchased from Wafer Technology, UK (charge mobility $\geq 4200 \mathrm{~cm}^{2} \mathrm{~V}^{-1} \mathrm{~s}^{-1}, \pm 0.1^{\circ}$ misorientation). The InP (001) crystal was in situ cleaned using a procedure reported by Sung et al., involving cycles of $\mathrm{Ar}^{+}$ion bombardment for contaminant removal and annealing for surface restoration. ${ }^{1}$ Such cleaning procedure was performed by low energy $(30 \mathrm{eV}) \mathrm{Ar}^{+}$bombardment at an angle of $45^{\circ}$ with respect to the normal surface, under an Ar pressure of $3 \times 10^{-6}$ over $10 \mathrm{~min}$. The $\mathrm{Ar}^{+}$bombardment was followed by annealing at $573 \mathrm{~K}$ for another $10 \mathrm{~min}$. Cycles of ion bombardment and annealing were performed to obtain a clean surface. ${ }^{2}$ Immediately after cleaning, the InP(001) crystal was transferred into an adjacent XPS analysis chamber to confirm surface cleanliness and absence of any surface contaminants originated from crystal exposure to ambient air conditions before introduction into the XPS system. Afterwards, the InP(001) crystal was transported into a reaction cell prior to $\mathrm{O}_{2}$ introduction. The crystal temperature was monitored by a K-type (chromel-alumel) thermocouple sandwiched between the $\mathrm{InP}(001)$ crystal and a molybdenum sample holder. Photoelectron spectra of $\mathrm{C} 1 \mathrm{~s}$ were recorded frequently, in which no carbon contamination was detected throughout the experimental procedures.

\section{Surface analysis}

The photoemission spectra were recorded using an ambient pressure X-ray Photoelectron Spectroscopy (APXPS) system (SPECS Surface Nano Analysis GmbH, Germany) at the Notre Dame Radiation Laboratory. The analysis chamber with a base pressure below $5 \times 10^{-10} \mathrm{mbar}$ was installed with an Al Ka X-ray source (1486.7 eV) and a Micro-FOCUS 600 monochromator (XR$\mathrm{MF})$. The reaction cell $\left(15 \mathrm{~cm}^{3}\right)$ was attached to a differentially-pumped, electrostatic lens system with a PHOIBOS 150 hemispherical energy analyzer. For a typical APXPS experiment, the X-ray source was kept at a power of $100 \mathrm{~W}(15 \mathrm{kV}, 6.7 \mathrm{~mA})$. More detailed descriptions of the experimental setup can be found in our previous work. ${ }^{3-5}$

The binding energy (BE) scale of photoelectron spectra was referenced to the Fermi edge of a clean $\mathrm{Au}(111)$ and also calibrated using the peak positions of $\mathrm{P} 2 \mathrm{p}_{3 / 2}(128.8 \mathrm{eV})$ corresponding to the bulk P-In bond ${ }^{6-10}$. Note that, at high temperatures $(>673 \mathrm{~K}$ ) where there surface P depletion became substantial, the BE calibration was based on the assumption that the spectral shift was the same as that of $673 \mathrm{~K}$. SpecsLab2 and CasaXPS software were used for spectral fittings, where a flexibility of 0.1-0.2 eV was typically used for the BE and full width at half-maximum (FWHM). Peak interpretations were both referred to previous reports of InP-based surface analysis and our theoretical calculations of binding energies. The FWHM of the $\mathrm{Au} 4 \mathrm{f}_{7 / 2}$ peak was $0.5 \mathrm{eV}$ at a pass energy of $20 \mathrm{eV}$, while the inherent lifetime broadening of this peak has been reported to be $\sim 0.3$ $\mathrm{eV} .{ }^{11}$ All the high-solution photoemission spectra were recorded with a pass energy of $20 \mathrm{eV}$.

The experiments were performed under: 1) Isothermal conditions at room temperature (RT), in which the $\mathrm{O}_{2}$ pressure varied from ultra-high vacuum (UHV, $5 \times 10^{-10} \mathrm{mbar}$ ) to $5 \mathrm{mbar}$. Pressuredependent photoelectron spectra were recorded at UHV, 0.005, 0.05, 0.5, and 5 mbar after the 
stabilization of $\mathrm{O}_{2}$ pressure ( 20 min); 2) Isobaric conditions with the $\mathrm{H}_{2} \mathrm{O}$ pressure held constant at $0.1 \mathrm{mbar}$ and the temperature adjusted from RT to $773 \mathrm{~K}$. The sample was heated at a rate of 5 $\mathrm{K} / \mathrm{min}$ followed by $20 \mathrm{~min}$ of stabilization time and temperature-dependent photoelectron spectra were recorded between $373 \mathrm{~K}$ and $773 \mathrm{~K}$. While the acquisition time for a typical set of spectra were less than $0.5 \mathrm{~h}$, extended recording time $(\sim 1 \mathrm{~h})$ was used at high pressures of $\mathrm{O}_{2}(>1 \mathrm{mbar})$. No time-dependent compositional changes were observed in the isothermal study at RT, even with exposures up to several hours. In the isobaric experiment, however, time-dependent variations in the intensities of spectral peaks were observed because of ongoing reactions, especially at temperatures higher than $673 \mathrm{~K}$. Therefore, the photoemission spectra at $773 \mathrm{~K}$ in Fig. 2 mainly demonstrate the qualitative trend of the evolution of the InP surface chemistry and the exact spectra may vary by certain extent depending on the heating time at high temperature.

The evolutions of In $4 \mathrm{~d}$ photoelectron spectra under isothermal and isobaric conditions are shown in Figure S1. Additionally, in order to confirm the absent of any charging effect on the surface, the In $3 \mathrm{~d}$ spectra obtained after the $\operatorname{InP}(100)$ oxidation in $0.1 \mathrm{mbar}_{2}$ at $773 \mathrm{~K}$ was irradiated by low energy electrons produced by a flood gun. No changes in In $3 \mathrm{~d}$ spectra recorded with and without the flood gun were observed as demonstrated in Figure S2, suggesting that the observed peak shift and broadening in the in-situ experiment was not due to charging effect.

\section{Measurement of work function:}

Single crystals of $\mathrm{Cu}(111), \operatorname{Ag}(111), \operatorname{Pt}(111)$, and $\mathrm{Au}(111)$ were purchased from Goodfellow, USA. They were cleaned using standard procedures by sputtering and annealing cycles prior to introduction into the reaction cell as the reference samples for work function measurement. $\mathrm{Ar}^{+}$ bombardment was followed by annealing and repeated over a few cycles. The following parameters were used: $1 \mathrm{keV}$ (accelerating voltage of $\mathrm{Ar}^{+}$) and $800 \mathrm{~K}$ (annealing temperature, $\mathrm{Cu}(111)), 1 \mathrm{keV}$ and $800 \mathrm{~K}(\mathrm{Ag}(111)), 1.25 \mathrm{keV}$ and $1100 \mathrm{~K}(\mathrm{Pt}(111))$, and $0.5 \mathrm{keV}$ and $1100 \mathrm{~K}$ $(\mathrm{Au}(111))$. Surface cleanliness was monitored also by taking photoelectron spectra. Within the detection limit, no contaminants were observed in the $\mathrm{C} 1 \mathrm{~s}, \mathrm{~N} 1 \mathrm{~s}$, or $\mathrm{O} 1 \mathrm{~s}$ regions in the survey spectra. Two gases, $\mathrm{O}_{2}(99.993 \%)$ for $\mathrm{InP}$ oxidation and $\mathrm{Ar}$ (99.999\%) for probing of work function were used as received. A residual gas analyzer (RGA) connected to a differential pumping stage monitored the purities of $\mathrm{O}_{2}$ and $\mathrm{Ar}$ in the reaction cell. No contaminants were measured above the detection limit of the RGA.

Changes in surface work functions were determined from the photoelectron spectra of gasphase $\mathrm{Ar}$ at the near-surface region of the $\mathrm{InP}(001)$ crystal, where these Ar molecules are not pinned to the Fermi level but to that of the vacuum level of the surface in contact or at the vicinity. Therefore, the binding energy of gas phase Ar has a linear correlation with the work function of surface of interest. This method has previously been used for liquid surfaces ${ }^{12,13}$ and nanoparticles. ${ }^{14,15}$ In this study, we estimated the work functions of $\mathrm{InP}(001)$ from the $\mathrm{BE}$ shift of the $\mathrm{Ar} 2 \mathrm{p}_{3 / 2}$ peak obtained under an $\mathrm{Ar}$ pressure of 0.5 mbar in the reaction cell. The changes in the $\mathrm{BE}$ of the near-surface Ar atoms were correlated to the work function of a material surface. ${ }^{14,15}$ By using the reference samples whose work functions are well-known, the BE of Ar can be directly converted into the work function of the $\mathrm{InP}(001)$ surface. Single crystals of $\mathrm{Cu}, \mathrm{Ag}, \mathrm{Pt}$, and $\mathrm{Au}$ with (111) orientations have been reported to possess work function of $4.85 \pm 0.10,{ }^{16-18} 4.60 \pm 0.16,{ }^{18-21} 5.90 \pm$ 
$0.20,{ }^{14,22,23}$ and $5.27 \pm 0.12 \mathrm{eV},{ }^{14,18,21,24-30}$ respectively. By plotting these values as a function of the $\mathrm{BE}$ of the $\mathrm{Ar} 2 \mathrm{p}_{3 / 2}$ peak, the following linear dependence was obtained:

$W F=-1.206 B E+299.0 \quad($ Equation 1)

where WF represents the work function of a particular sample and $\mathrm{BE}$ represents the $\mathrm{BE}$ of the $\operatorname{Ar} 2 p_{3 / 2}$ peak. The work functions of $\operatorname{InP}(001)$ under various experimental conditions were estimated by treating the InP in the reaction cell in an $\mathrm{O}_{2}$ environment, followed by the introduction of $0.5 \mathrm{mbar} \mathrm{Ar}$ (with the same pressure of $\mathrm{O}_{2}$ ). The Ar $2 \mathrm{p}$ spectrum under each experimental condition was then recorded and shown in Figure S3. The BE of Ar 2p $3 / 2$ was extracted and the work function of InP surface under different conditions can be determined (Equation 1) and shown in Fig. 4.

\section{Thickness of oxide/phosphate:}

Assuming that homogeneous and uniform oxide layers were formed on the $\operatorname{InP}(001)$ surface, the thickness of oxide layer $(d)$ can be estimated from integrated peak intensities: ${ }^{6,31-33}$

$I=I^{o x} \exp \left(-\frac{d}{\lambda \cdot \sin (\alpha)}\right)$

(Equation 2)

where $\lambda$ is the inelastic mean free path (IMFP) of photoelectrons, i.e., $\sim 26$ and $\sim 34 \AA$ for photoelectrons from the In $3 \mathrm{~d}_{5 / 2}$ and In $4 \mathrm{~d}_{7 / 2}$ electronic states, respectively. ${ }^{34}$ The integrated photoelectron peak intensities, $I$ and $I^{o x}$, were corresponded to the InP surface with and without oxide films, respectively. The value of $\sin (\alpha)(\alpha$ is the take-off angle of photoelectrons with respect to a surface) was 1 for our experimental setup. The thickness of surface oxides/phosphate can be estimated by dividing the oxide thickness by the height of one atomic layer (1.5 ̊ for indium phosphide) ${ }^{6}$

\section{Oxygen uptake probability ( $\mathrm{S}$, reaction probability):}

The oxygen uptake probability can be related to the reaction probability of $\mathrm{O}_{2}$ with the InP(001) surface under specific experimental conditions. We estimated this probability using the following equation: ${ }^{6}$

$$
S=\frac{\theta \bullet N}{R \bullet t}
$$

$\mathrm{N}$ is the site density $\left(\mathrm{cm}^{-2}\right)$ and has a value of $5.8 \times 10^{14} \mathrm{~cm}^{-2}$, which corresponds to the number of $(1 \times 1)$ unit cells in $\mathrm{a} \mathrm{cm}^{2}$ of the $\operatorname{InP}(001)$ plane. $\mathrm{R}$ is the collision rate of $\mathrm{O}_{2}$ molecules with the surface $\left(3.4 \times 10^{18}\right.$ at $300 \mathrm{~K}$ and a pressure of $\left.0.005 \mathrm{mbar}\right)$, which is proportional to the pressure of $\mathrm{O}_{2} \theta$ is the oxide coverage calculated by the method mentioned above, $\mathrm{t}$ is time in seconds. In a typical experiment, 40 min was used for conditions other than 5 mbar at room temperature, which took $\sim 60 \mathrm{~min}$. 

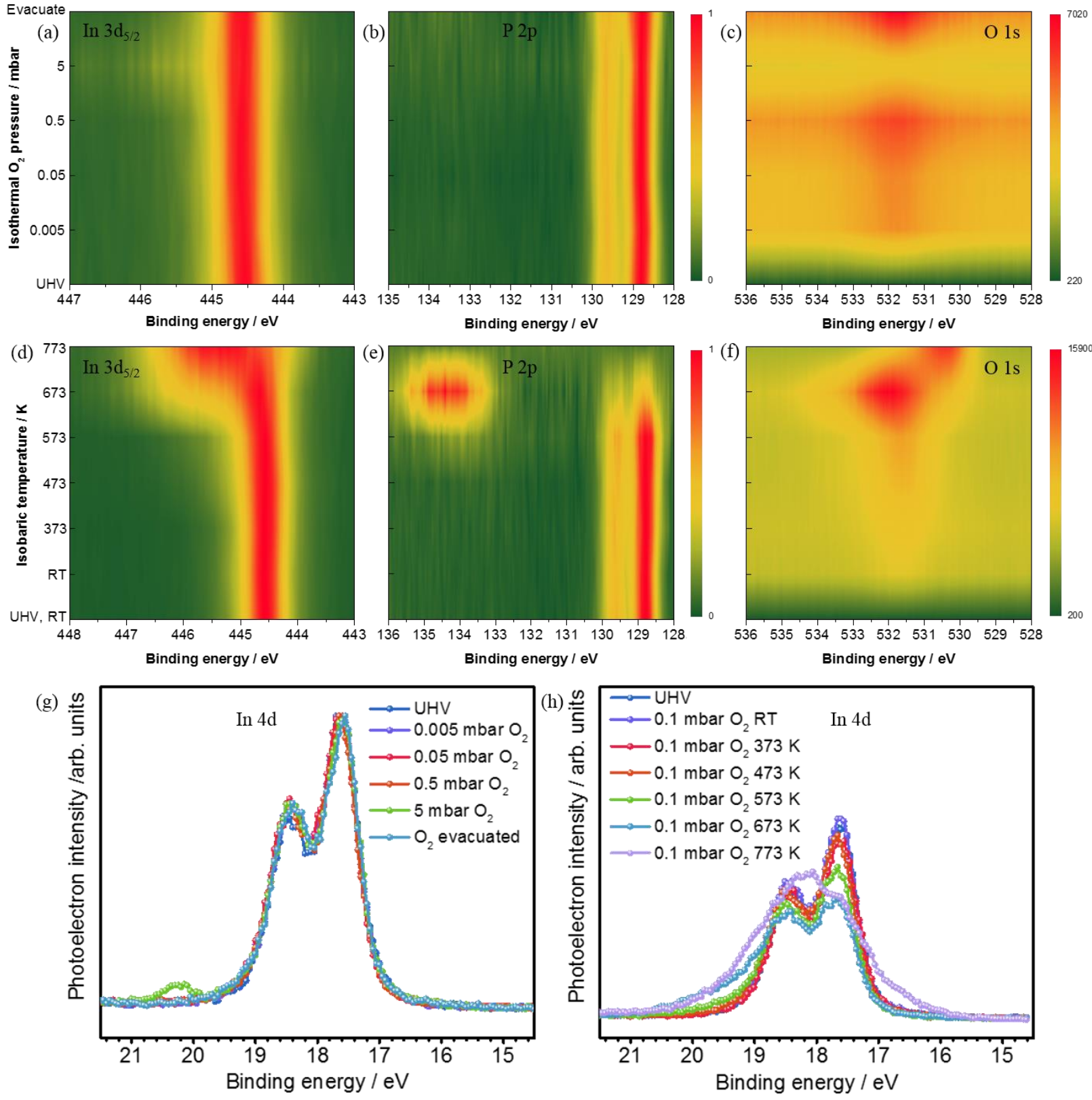

Figure S1. Evolution of photoelectron spectra under isothermal and isobaric conditions. ac) Contour plots of In $3 \mathrm{~d}_{5 / 2}, \mathrm{P} 2 \mathrm{p}$ and $\mathrm{O} 1 \mathrm{~s}$ under isothermal conditions (RT, UHV-5mbar of $\mathrm{O}_{2}$ ). d-f) Contour plots of In $3 \mathrm{~d}_{5 / 2}, \mathrm{P} 2 \mathrm{p}$ and $\mathrm{O} 1 \mathrm{~s}$ under isobaric conditions (RT-773 K in 0.1 mbar of $\left.\mathrm{O}_{2}\right) . \mathrm{g}, \mathrm{h}$ ) Evolution of the photoemission spectra of In $4 \mathrm{~d}$ under isothermal and isobaric conditions, respectively. Note that, for presentation purpose, spectra in a, b, d, e and $g$ were normalized from 0 to 1 . $a$ and $b$ share the same color bar; $d$ and e share the same color bar. 
Chemical changes in surface In atoms only occur at the topmost atomic layers under isothermal conditions and can be inferred by the slight spectral shift towards the higher binding energy side (a); changes in $\mathrm{P}$ are implicated by the less-resolved separations between $\mathrm{P} 2 \mathrm{p}_{3 / 2}$ and $\mathrm{P} 2 \mathrm{p}_{1 / 2}$, and a gradually emerged feature at $\sim 134 \mathrm{eV}\left(\mathrm{a}, 5 \mathrm{mbar}\right.$ of $\left.\mathrm{O}_{2}\right)$. The apparent signal intensity change in $\mathrm{O} 1 \mathrm{~s}$ (c, non-normalized) at $5 \mathrm{mbar}$ of $\mathrm{O}_{2}$ is an artificial effect due to a more prominent scattering effect between outgoing photoelectrons and environmental $\mathrm{O}_{2}$ molecules. Significant spectral changes were observed above $573 \mathrm{~K}$ in 0.1 mbar of $\mathrm{O}_{2}$, where $\mathrm{PO}_{\mathrm{x}}$ units develop into 3D oxide network (d-f), which experience P-depletion (e) at temperatures between $673 \mathrm{~K}$ and $773 \mathrm{~K}$, leaving behind a $\mathrm{In}_{2} \mathrm{O}_{3}$ covered surface (d and f).

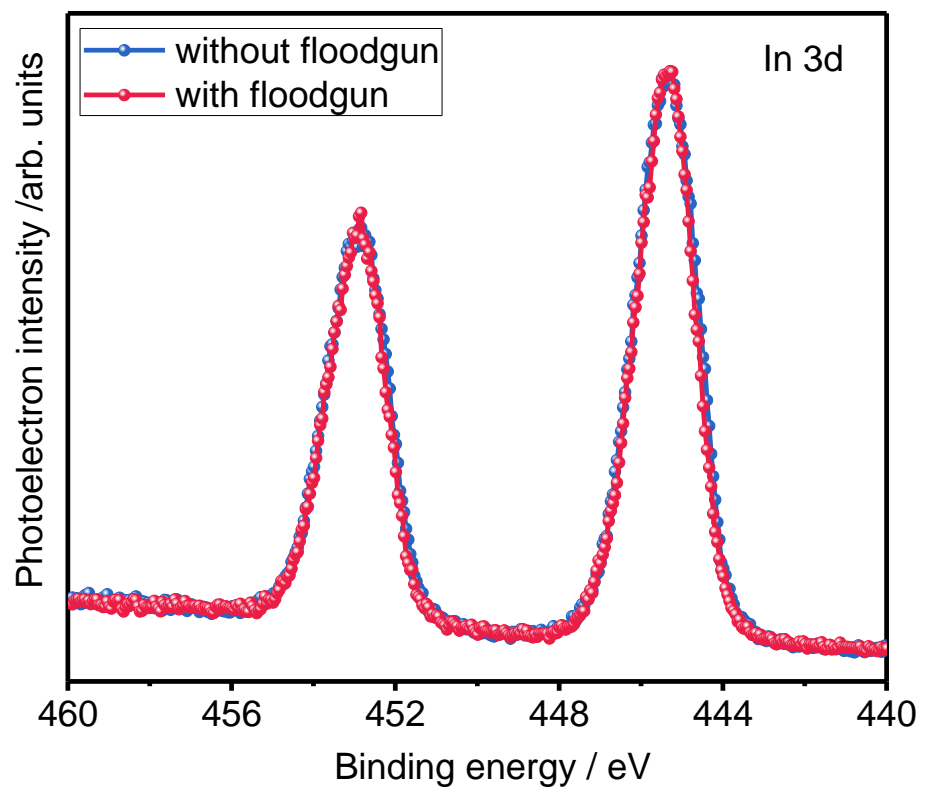

Figure S2. In 3d photoelectron spectra of the $\mathrm{InP}(001)$ surface after oxidation under an $\mathrm{O}_{2}$ pressure of 0.1 mbar at $773 \mathrm{~K}$ recorded under UHV conditions with and without a flood gun. 


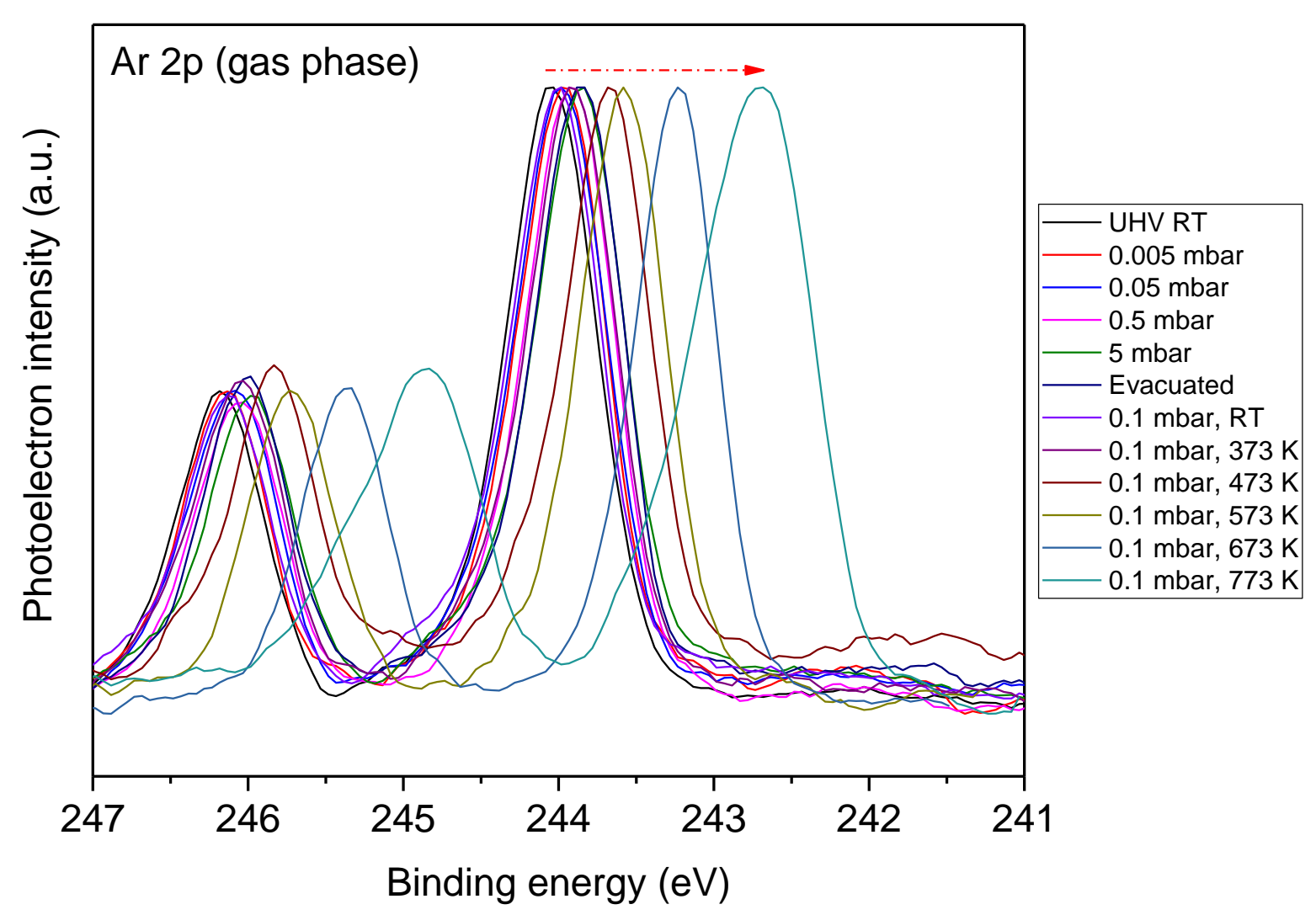

Figure S3. Evolution of Ar 2p gas phase photoemission spectra obtained under in-situ conditions while the InP was treated under different conditions. The photoemission spectra were smoothened by adjacent averaging (points of window, 5) and normalized from 0 to 1. The red arrow is used as a guidance to show the evolution of the peak maxima of $\operatorname{Ar} 2 \mathrm{p}_{3 / 2}$.

III. Theoretical calculations of the oxidation of InP $(001)-\delta(2 \times 4)$ and InP (001)$(1 \times 2)$, stability of model structures and the core-level binding energies

In order to construct oxygen adsorption behaviour, two types of well-known $\operatorname{InP}(001)$ surface structural models were used, In rich $(1 \times 2)$ reconstructed surface and $(2 \times 4)$ mixed dimer surface. The $\delta(2 \times 4)$ surface unit-cell were taken for both structural models to ensure calculation consistency. On these surfaces, oxygen atoms were adsorbed at the positions described in our previous study, ${ }^{35}$ where the oxygen coverage was varied from 1 to 4 per $\delta$ $\delta(2 \times 4)$ cell incrementally (one oxygen per cell corresponds to theta $=0.1) .{ }^{35}$ The full coverage ( 8 oxygen per $\delta(2 \times 4)$ cell) structures were also investigated in this study (corresponding to theta $=1$ ).

In order to describe ions, ultrasoft pseudopotentials were used, where the electronic eigenstates were expanded by planewaves with the cutoff energy of 30Ry and the cutoff energy for charge density of 240Ry. K-point sampling on 6x3x1 uniform grid was taken for $\delta(2 \times 4)$ surface structural models. For each system, the atomic configuration was relaxed until the residual force is reduced to less than $1.0 \times 10^{-4}$ AU using BFGS method (quasiNewton algorithm). In this study, we excluded the high energy configuration such as \#4 in 
Fig. 3. For each structural model, $\mathrm{O} 1 \mathrm{~s}$ and $\mathrm{P} 2 \mathrm{p}$ core-level binding energy shift was calculated using the final state theory. ${ }^{36}$

The surface structures with adsorbed oxygen were modeled as repeated slabs and longrange Coulomb interactions between adjacent unit-cells along c-axis (perpendicular to surface) were treated by effective screening medium (ESM). Our choice of effective screening medium (ESM) configuration is as follows: ESM metal electrode is located in the backside of our slab model and the Coulomb interaction along c-axis is cut-off at the boundary of simulation box. In this way, one can monitor the electrostatic potential of the surface model that can be estimated against the ESM electrode placed in the back side of slab, and there is no Coulomb interactions between the surface and their periodic images along c-axis ensuring that polarization due to core-hole (pseudopotential) created by X-ray photons does not directly interact with their periodic images.

At the high temperature experiments, thickness of surface oxide/phosphate were estimated to grow more than a few tens of nanometers, where the structure is expected to be close to the amorphous bulk and the stoichiometry is likely to deviate from the well-defined crystalline forms such as $\mathrm{In}_{2} \mathrm{O}_{3} / \mathrm{InPO}_{4}$. In this study, we have generated three amorphous oxide structural models and calculated their $\mathrm{BEs}$ for $\operatorname{In}_{2} \mathrm{O}_{3}, \operatorname{InPO}_{4}$ and $\operatorname{In}\left(\mathrm{PO}_{3}\right)_{3}$. In order to generate the amorphous structures, simulated annealing was performed at $\mathrm{T}=5000 \mathrm{~K}$, followed by cooling to $\mathrm{T}=800 \mathrm{~K}$ using velocity scaling thermostat with the relaxation time scale of $t=50000$ au.

The complete screening theory used in this study does not provide a direct energy reference. Therefore, we adjusted theoretical $\mathrm{P} 2 \mathrm{p}_{3 / 2} \mathrm{BE}$ of crystalline InP to our experimentally observed peak position of $128.8 \mathrm{eV}$, together with a spin-orbit splitting value of $0.84 \mathrm{eV}$. For this theoretical calculation, we used 216 atom supercell and 2x2x2 k-points sampling. For $\mathrm{O} 1 \mathrm{~s} \mathrm{BE}$, our experimental systems do not contain the well-defined crystal oxide. However, the observed $\mathrm{O} 1 \mathrm{~s} \mathrm{BE}$ peak at $\mathrm{T}=573 \mathrm{~K}, 531.64 \mathrm{eV}$, is very close to the published value for $\mathrm{InPO}_{4}$ of $531.8 \mathrm{eV} .{ }^{9}$ In this study, we adjusted the $\mathrm{O} 1 \mathrm{~s}$ BE peak position of amorphous $\mathrm{InPO}_{4}$ to $531.64 \mathrm{eV}$, which provides a very good agreement between the calculated peak position of amorphous $\mathrm{In}_{2} \mathrm{O}_{3}$ and the experimentally observed peak position for $\mathrm{T}=773 \mathrm{~K}$, which is phosphorus-depleted indium oxide. For this theoretical calculation, we used 192 atom supercell with 2x2x2 k-points sampling.

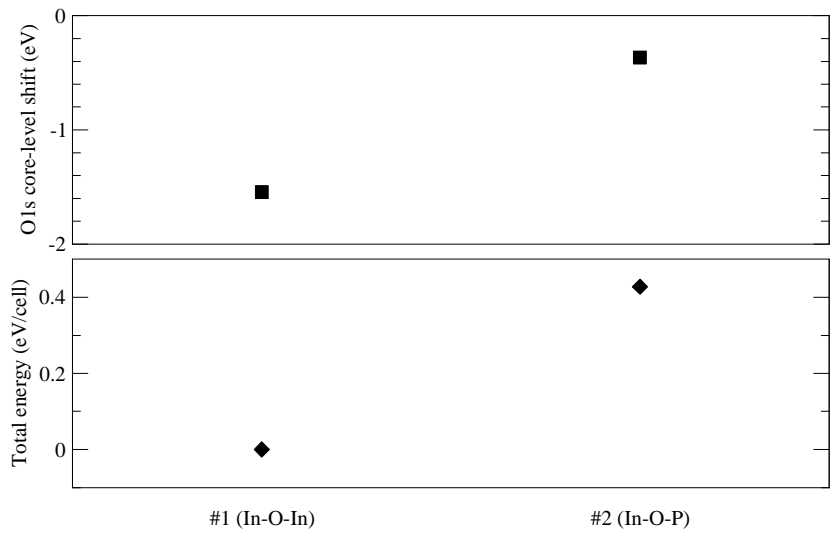

Figure S4. Total energy of an oxygen adsorbed on InP (001)-(1x2) surface structures (lower panel) as well as their core-level BE shift of $\mathrm{O} 1 \mathrm{~s}$ (upper panel). The configuration \#1 is about $0.4 \mathrm{eV} / \mathrm{cell}$ more stable than the configuration \#2, while the $\mathrm{O} 1 \mathrm{~s} \mathrm{BE}$ of the configuration \#2 is about $1 \mathrm{eV}$ higher than that of configuration \#1. 

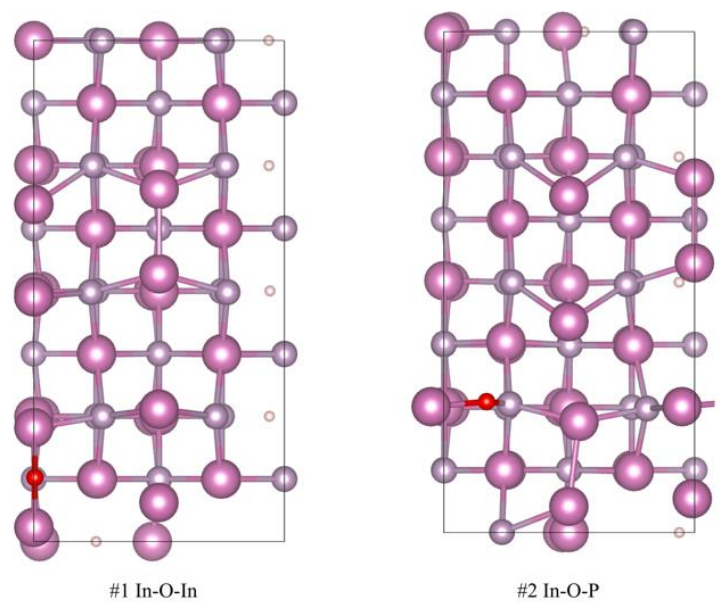

\#2 In-O-P

Figure S5. One oxygen adsorbed structures of InP (001)-(1x2) surfaces. Red, purple, and grey, spheres denote oxygen, indium and phosphorus atoms, respectively.

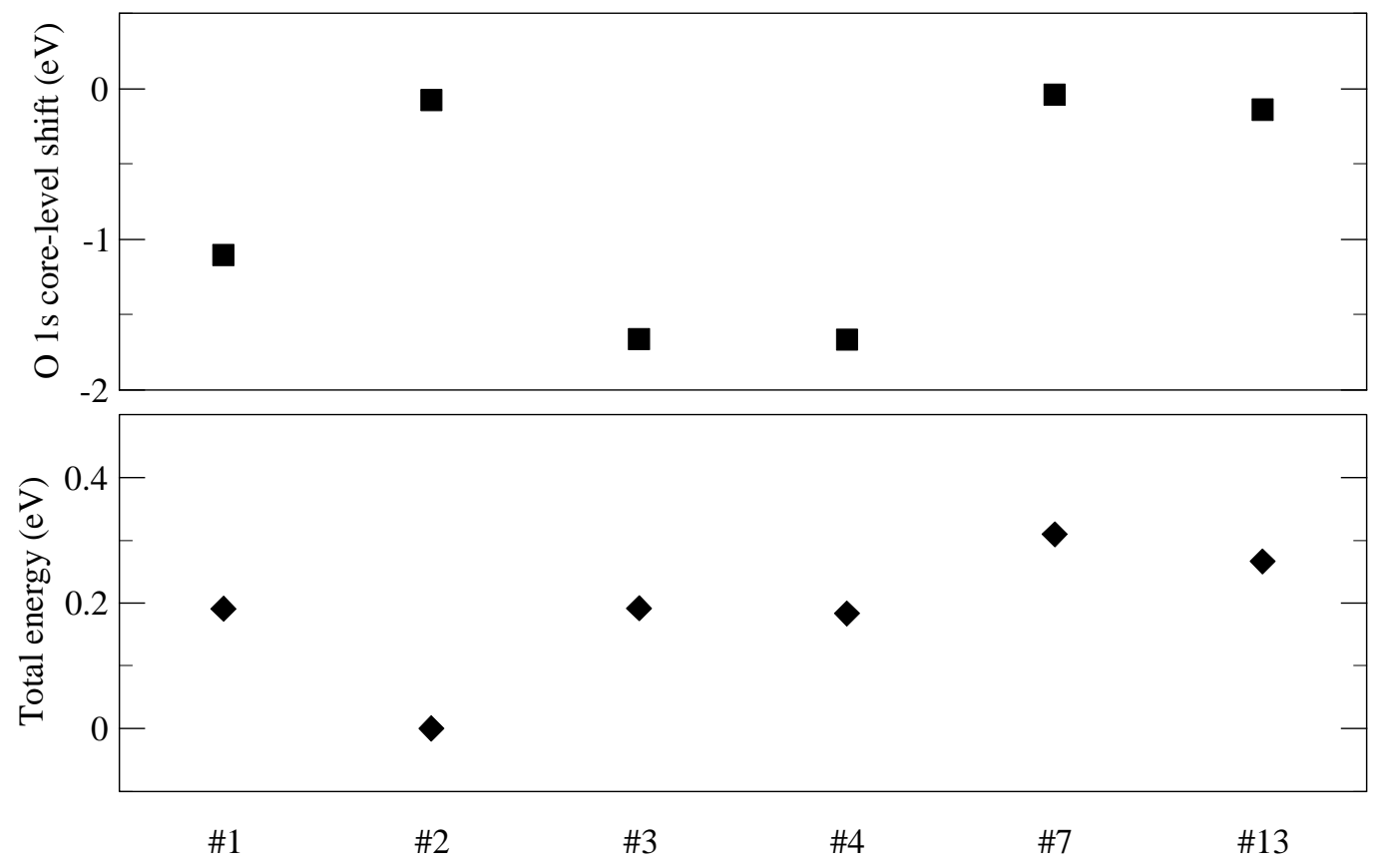

Figure S6. Total energy of InP (001)- $\delta(2 \times 4)$ surface structures (lower panel) as well as their corelevel BE shift (O 1s, upper panel). The \#2 configuration, where the oxygen atom is bound to In and $\mathrm{P}$ of the mixed dimer, is the most stable configuration. General trend of $\mathrm{BE}_{\mathrm{In}-\mathrm{O}-\mathrm{P}}>\mathrm{BE}$ In-O-In is clearly seen. 


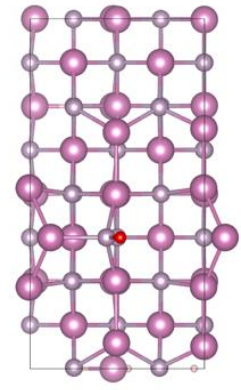

\#1

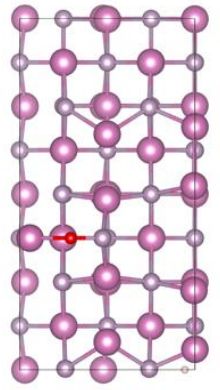

\#2

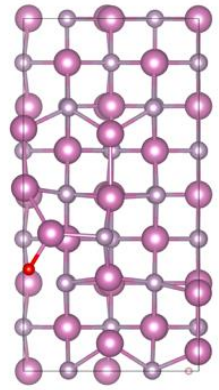

\#3

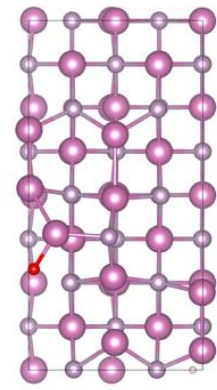

\#4

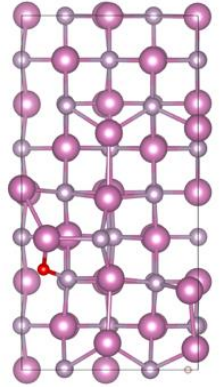

\#7

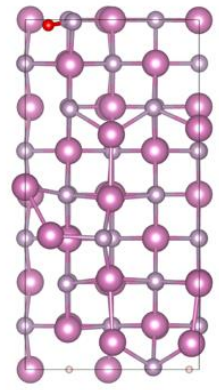

$\# 13$

Figure S7. One oxygen adsorbed surface structures of InP (001)- $\delta(2 x 4)$. Red, purple, and grey, spheres denote oxygen, indium and phosphorus atoms, respectively. \#3 and \#4 started from different initial configurations but were relaxed into the identical structures. In \#1, the oxygen atom is adsorbed on the phosphorus atom of a mixed dimer; while in \#2, the oxygen atom is adsorbed in between the phosphorus and indium atoms of a mixed dimer.
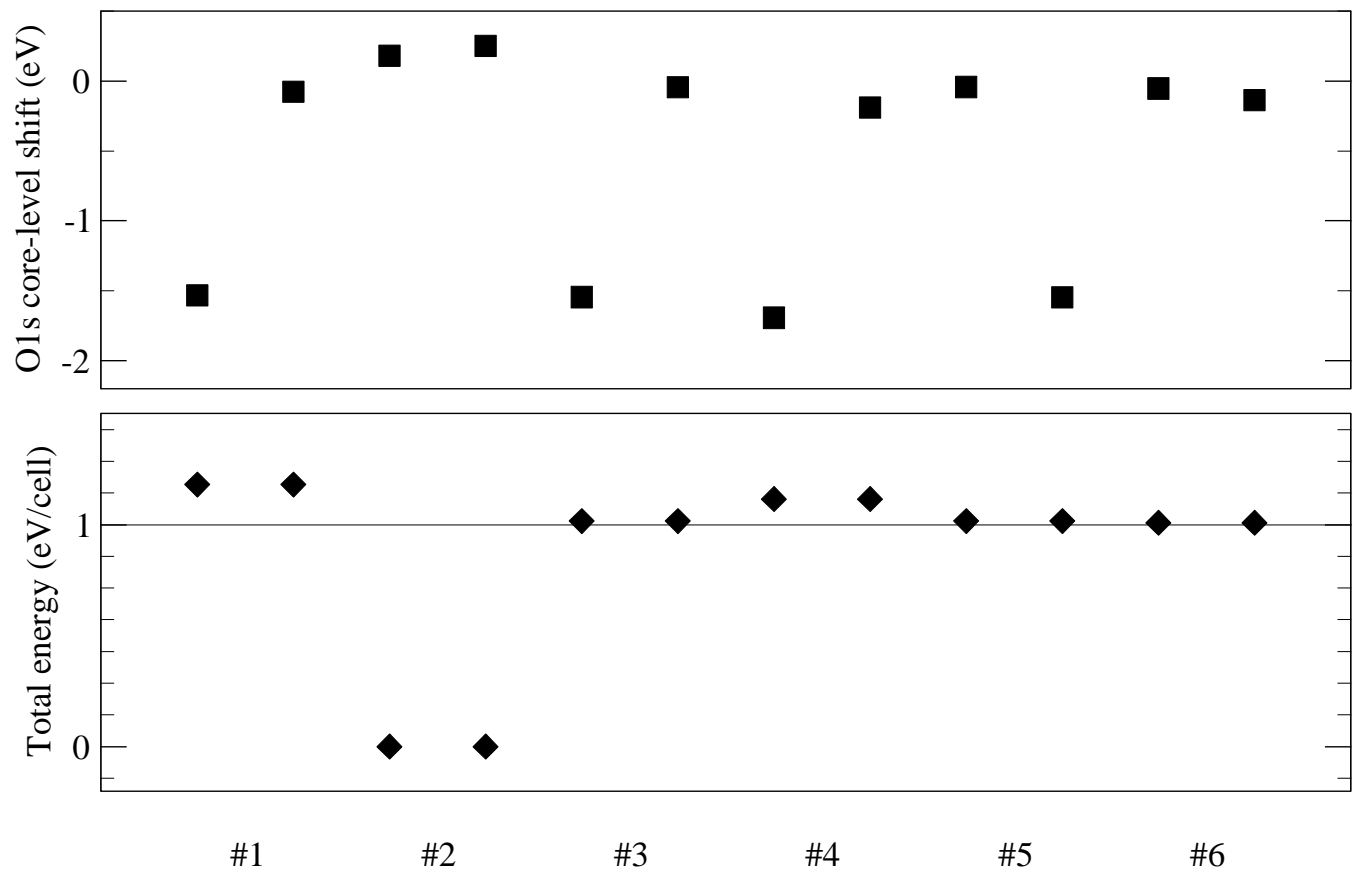

Figure S8. Total energy of two oxygen atoms adsorbed $\operatorname{InP}(001)-\delta(2 \mathrm{x} 4)$ surface structures (lower panel) as well as their core-level BE shifts (O 1s, upper panel). The configuration \#2, where two oxygen atoms are both bound to the phosphorous atom of mixed dimer, is now about $1 \mathrm{eV} / \mathrm{cell}$ more stable than any other configurations. The $\mathrm{O} 1 \mathrm{~s}$ BEs are clearly separated in two groups, InO-In and In-O-P. 


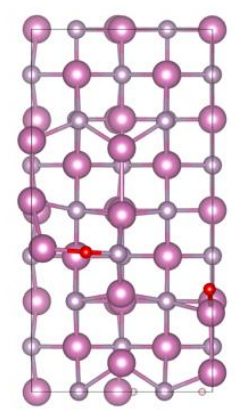

$\# 1$

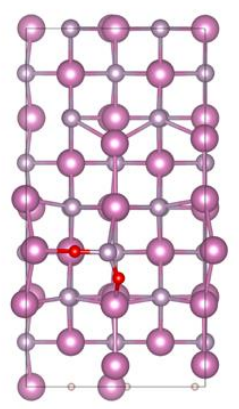

\#2

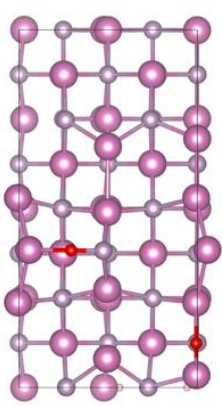

\#3

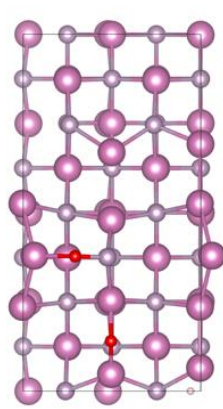

\#4

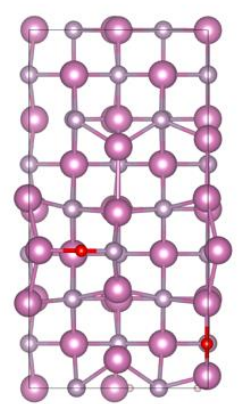

\#5

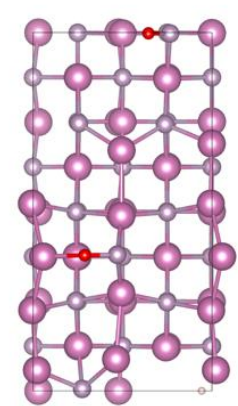

\#6

Figure S9. Two oxygen atoms adsorbed surface structures of InP (001)- $\delta(2 x 4)$. Red, purple, and grey, spheres denote oxygen, indium and phosphorus atoms, respectively.
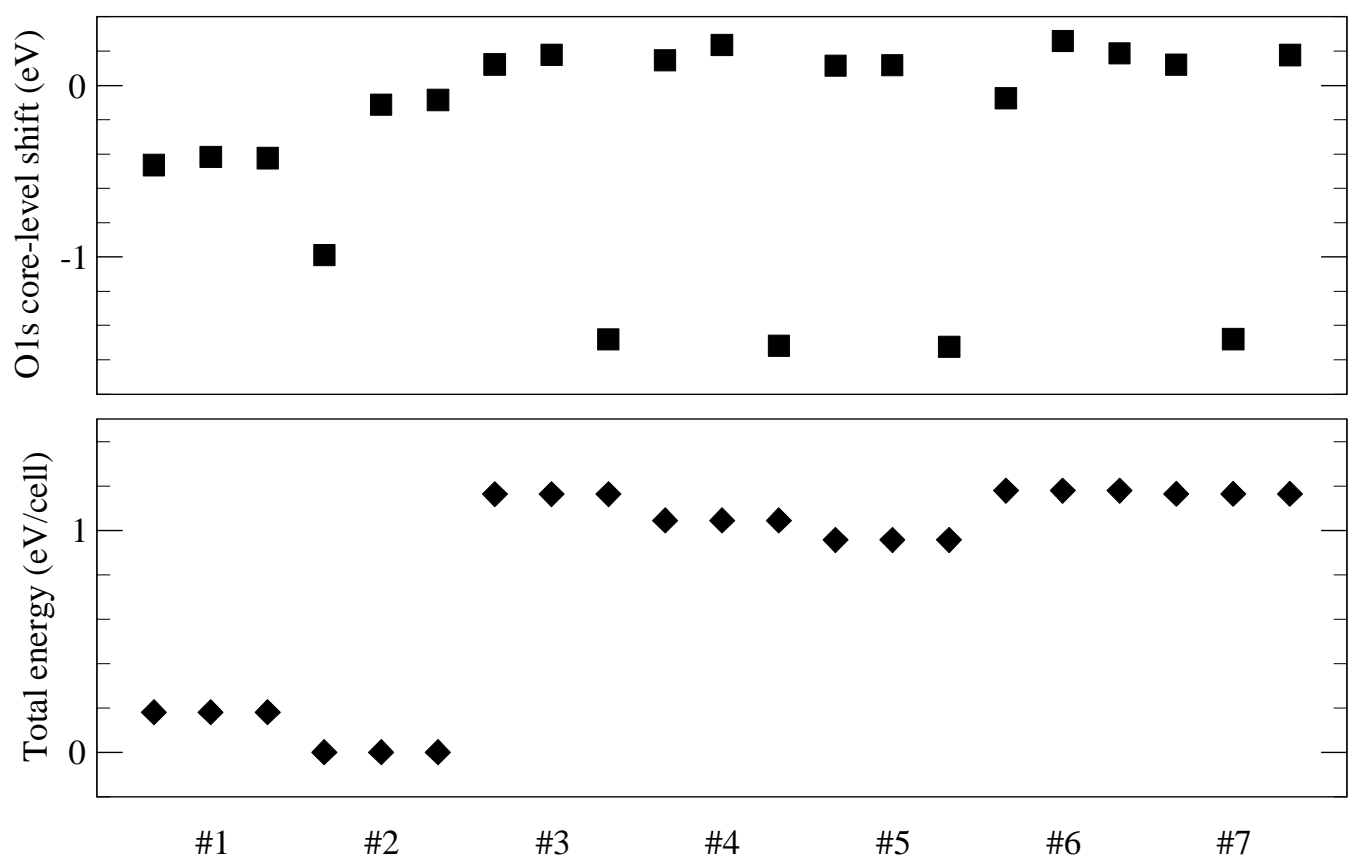

Figure S10. Total energy of three oxygen atoms adsorbed $\operatorname{InP}(001)-\delta(2 x 4)$ surface structures (lower panel) as well as their core-level BE shifts (O 1s, upper panel). The configuration \#2 is the most stable followed by \#1. The total energies of these configurations are separated by only about $0.2 \mathrm{eV} /$ cell, while the rest of configurations are about $1 \mathrm{eV} /$ cell higher. \#2 configuration has an oxygen atoms that is only bound to the phosphorous atom of mixed dimer, while \#1 has three InO-P configurations (see S13). The trend in BE shifts are about the same with above (S4 S8), except that \#1 exhibits smaller BE shifts than the other In-O-P configurations and the oxygen atom, which is bound only to the phosphorous atom of the mixed dimer and shows a BE shift that is significantly lower than In-O-P configurations in \#3-\#7. 


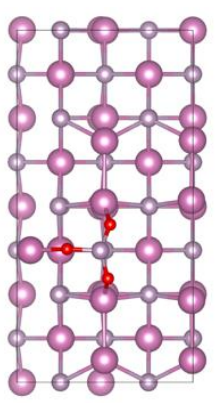

$\# 1$

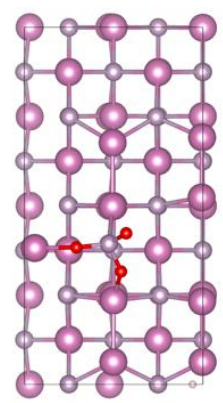

\#2

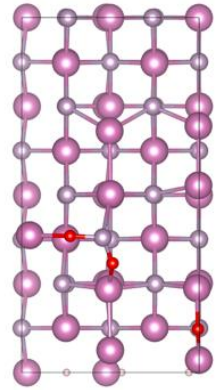

\#3

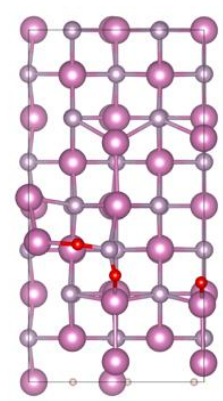

\#4

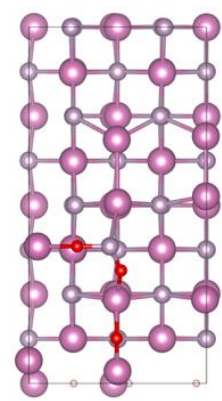

\#5

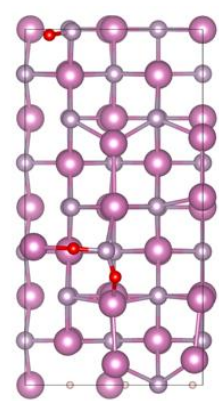

\#6

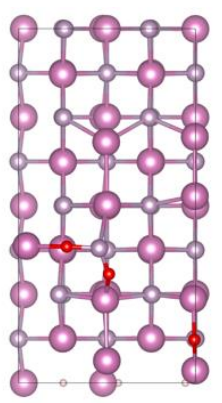

\#7

Figure S11. Three oxygen atoms adsorbed surface structures of InP (001)- $\delta(2 x 4)$. Red, purple, and grey, spheres denote oxygen, indium and phosphorus atoms, respectively.

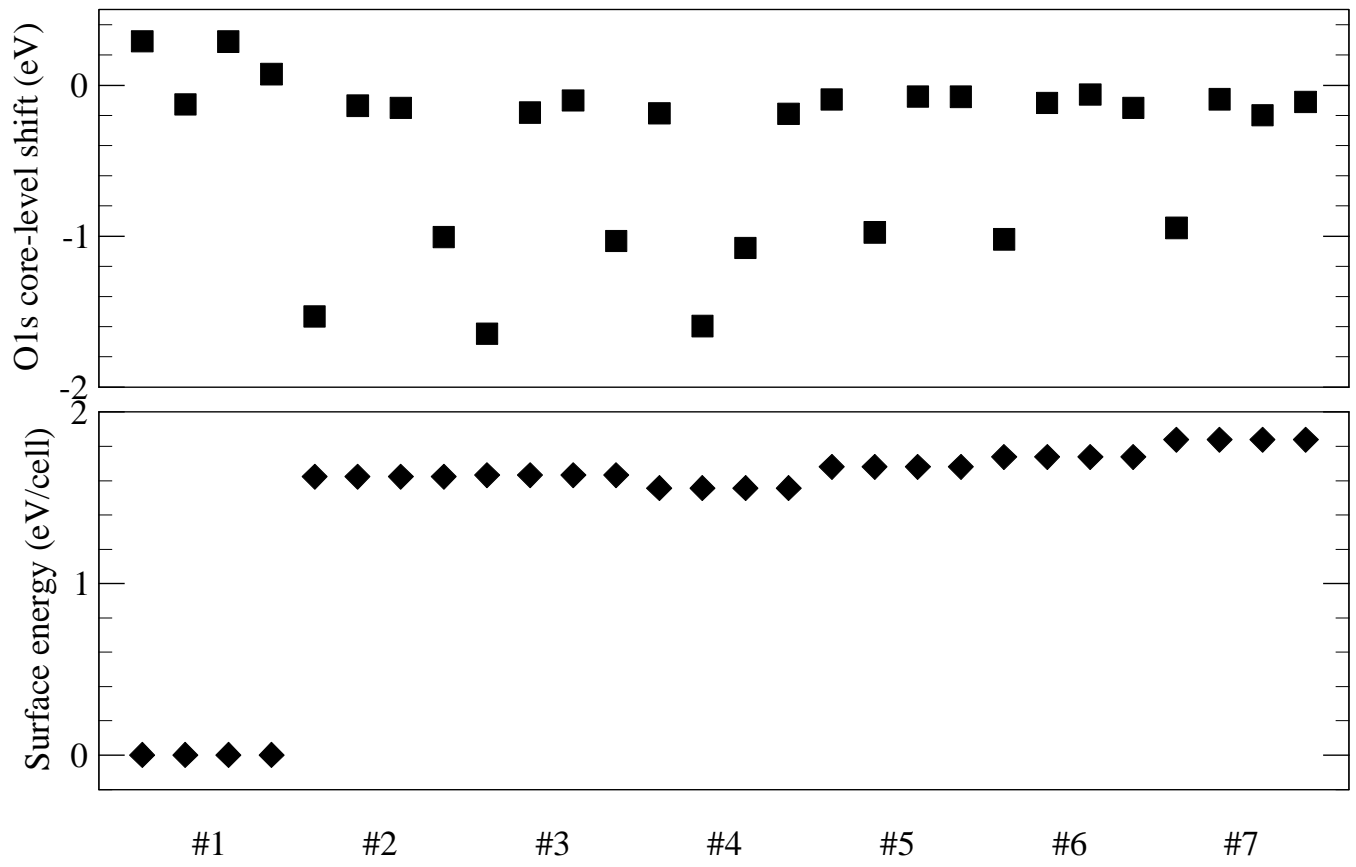

Figure S12. Total energy of four oxygen atoms adsorbed $\operatorname{InP}(001)-\delta(2 x 4)$ surface structures (lower panel) as well as their core-level BE shifts (O 1s, upper panel). For \#1 configuration, where oxygen atoms are bound to the phosphorous atom of the mixed dimer in tetrahedral configuration, is about $1.5 \mathrm{eV} /$ cell more stable than any other configuration. BEs of $\mathrm{O} 1 \mathrm{~s}$ of \#1 configuration are slightly higher than the other In-O-P configurations seen in \#2-\#7. 


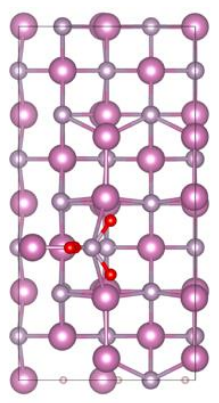

\#1

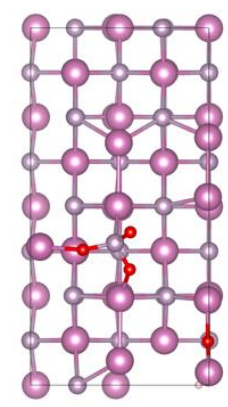

\#2

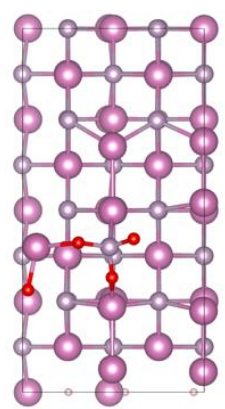

\#3

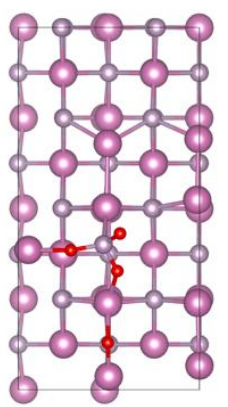

\#4

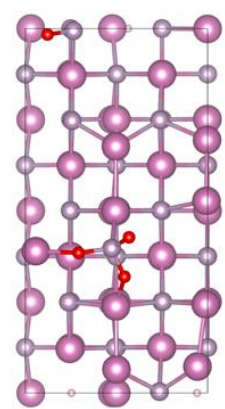

\#5

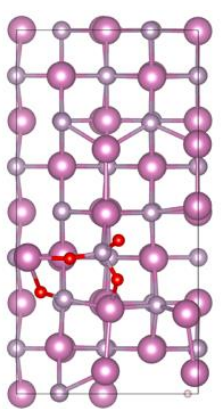

\#6

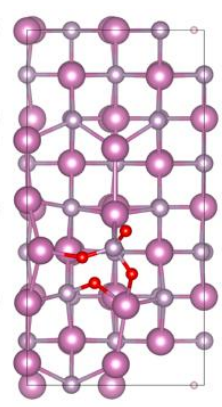

$\# 7$

Figure S13. The four oxygen atoms adsorbed surface structures of $\operatorname{InP}(001)-\delta(2 x 4)$. Red, purple, and grey, spheres denote oxygen, indium and phosphorus atoms, respectively. There were five more structures studied but not shown here because they did not provide unique properties in terms of their stability (similar as configurations \#2-\#7) or O 1s core-level BE shift.

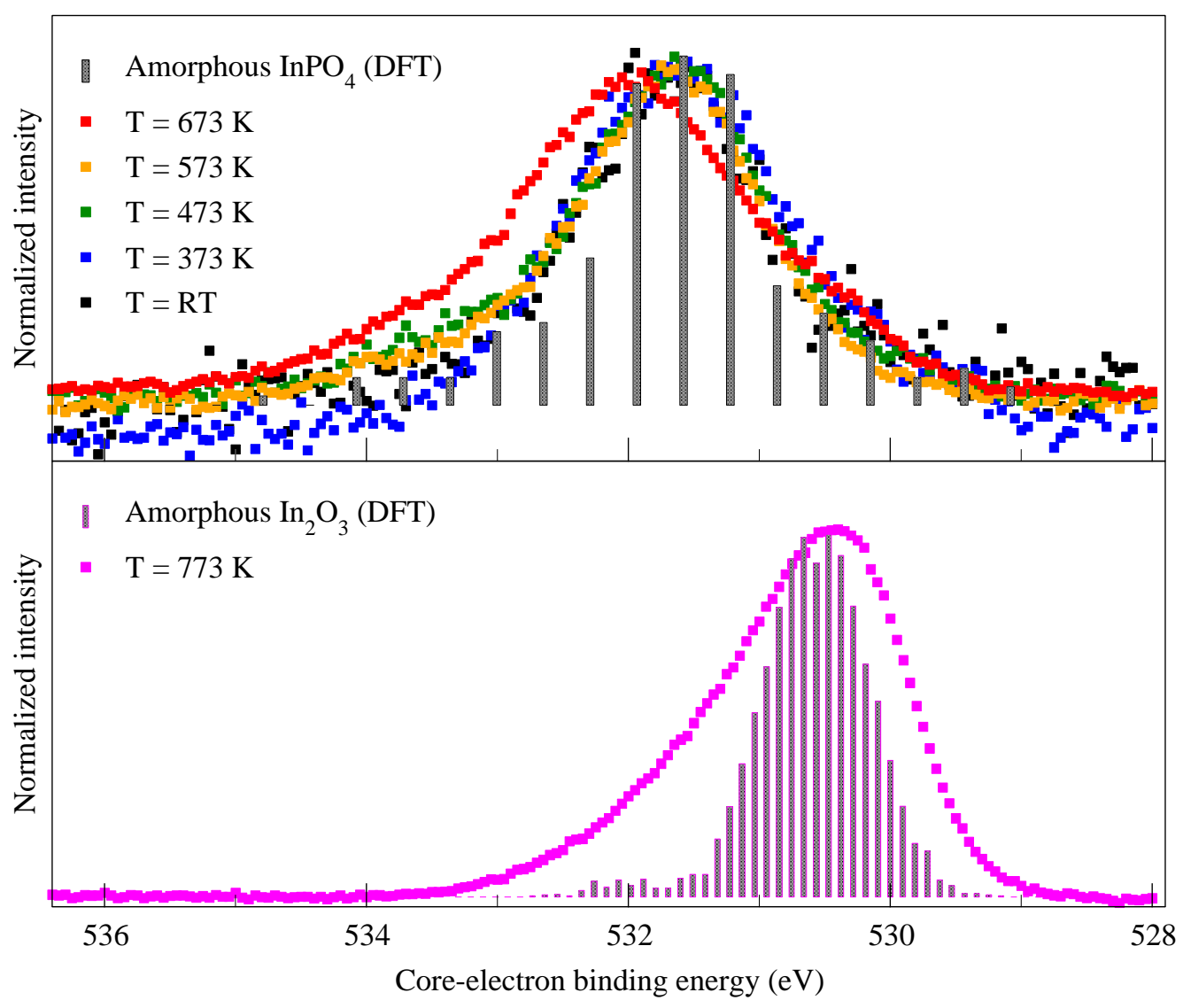

Figure S14. Calculated O 1s BE histogram (bars) and experimental data (symbol envelope). The experimental data is for isobaric measurements as indicated in the figure. The peak heights were normalized to the same between calculation and experiment. 


\begin{tabular}{|c|c|c|c|c|}
\hline \multirow[t]{2}{*}{$\mathrm{O} 1 \mathrm{~s}$} & \multicolumn{2}{|l|}{ DFT } & \multicolumn{2}{|l|}{ EXP } \\
\hline & \begin{tabular}{|l} 
absolute \\
\end{tabular} & relative & absolute & relative \\
\hline $\mathrm{InPO}_{4}$ & $532.2 \mathrm{eV}$ & $\begin{array}{l}+2.0 \mathrm{eV} \\
(+25 \%)\end{array}$ & $531.8 \mathrm{eV}$ & $1.6 \mathrm{eV}$ \\
\hline $\mathrm{In}_{2} \mathrm{O}_{3}$ & Reference & $0.0 \mathrm{eV}$ & 530.2 & $0.0 \mathrm{eV}$ \\
\hline $\operatorname{In}\left(\mathrm{PO}_{3}\right)_{3}$ & $\begin{array}{l}534.3 / 536.0 \\
\mathrm{eV}\end{array}$ & $+4.1 / 5.8 \mathrm{eV}$ & N/A & N/A \\
\hline $\mathrm{P}_{2} \mathrm{O}_{5}$ & $\begin{array}{l}534.3 / 536.4 \\
\mathrm{eV}\end{array}$ & $+4.1 / 6.2 \mathrm{eV}$ & $\begin{array}{l}532.7 / 534.1 \\
\text { eV (powder) }\end{array}$ & $+2.5 / 3.9 \mathrm{eV}$ \\
\hline \multirow[t]{2}{*}{ P $2 p$} & \multicolumn{2}{|l|}{ DFT } & \multicolumn{2}{|l|}{ EXP } \\
\hline & absolute & relative & absolute & relative \\
\hline InP & reference & $0.0 \mathrm{eV}$ & $128.8 \mathrm{eV}$ & $0.0 \mathrm{eV}$ \\
\hline $\mathrm{InPO}_{4}$ & $134.5 \mathrm{eV}$ & $\begin{array}{l}+5.7 \mathrm{eV} \\
(+7.5 \%)\end{array}$ & $134.1 \mathrm{eV}$ & $+5.3 \mathrm{eV}$ \\
\hline $\operatorname{In}\left(\mathrm{PO}_{3}\right)_{3}$ & $136.3 \mathrm{eV}$ & $+7.5 \mathrm{eV}$ & N/A & N/A \\
\hline $\mathrm{P}_{2} \mathrm{O}_{5}$ & $136.5 \mathrm{eV}$ & $+7.7 \mathrm{eV}$ & $135.6 \mathrm{eV}$ & $+6.8 \mathrm{eV}$ \\
\hline \multirow[t]{2}{*}{ In $3 d$} & \multicolumn{2}{|l|}{ DFT } & \multicolumn{2}{|l|}{ EXP } \\
\hline & absolute & relative & absolute & relative \\
\hline InP & $444.5 \mathrm{eV}$ & $\begin{array}{l}-0.2 \mathrm{eV}(- \\
85 \%)\end{array}$ & $444.4 \mathrm{eV}$ & $-1.3 \mathrm{eV}$ \\
\hline $\mathrm{InPO}_{4}$ & reference & $0.0 \mathrm{eV}$ & $445.7 \mathrm{eV}$ & $0.0 \mathrm{eV}$ \\
\hline $\mathrm{In}_{2} \mathrm{O}_{3}$ & $444.5 \mathrm{eV}$ & $-1.2 \mathrm{eV}$ & $444.7 \mathrm{eV}$ & $-1.0 \mathrm{eV}$ \\
\hline $\operatorname{In}\left(\mathrm{PO}_{3}\right)_{3}$ & $446.1 \mathrm{eV}$ & $+0.4 \mathrm{eV}$ & N/A & N/A \\
\hline
\end{tabular}

Table S1. Theoretical (DFT/PBEGGE) and experimental O 1s, P 2p, In 3d core level binding energies of compounds containing indium, phosphorus and oxygen. The experimental values are from Hollinger et al. ${ }^{9}$ Absolute values of theoretical BEs are referenced to the experimental BEs for $\mathrm{InPO}_{4}\left(\mathrm{O}\right.$ 1s), InP (P 2p) and $\mathrm{InPO}_{4}$ (In 3d). Note: $\mathrm{P}_{2} \mathrm{O}_{5}$ sample in Ref. [9] is powder, which may have some disorder as the material tend to be glassy. Also, in Ref. [9], the sample $\mathrm{C} 1$ is denoted as $\mathrm{InP}_{3.1} \mathrm{O}_{9} \sim \operatorname{In}\left(\mathrm{PO}_{3}\right)_{3}$, however, the corresponding $\mathrm{O}$ 1s BE does not have two peaks corresponding to bridging/non-bridging $\mathrm{O}$, therefore, we assume that the sample has a significant 
disorder and does not corresponds to the crystal structure used in these BE calculations, which is taken from materialsproject.org (ID: mp-14535).

Note that the BE values in Ref. [9] were calibrated to surface adventitious carbon, different from the present experiment that is referred to the BE of In-P at $128.8 \mathrm{eV}$. Therefore, there absolute BE values maybe different between Ref. [9] and the present study, but the absolute BE changes with respect to $\mathrm{InP}, \triangle \mathrm{BE}$, are expected to be the same. Also note that the two $\mathrm{BE}$ calibration methods both have their shortcomings. In the case of Ref. [9], there may be differential charging effect between surface adventitious carbon and the targeting sample, especially for a semiconducting sample with poor conductivity (at high temperature with high coverage of oxides); the surface adventitious carbon and the targeting sample may refer to different Fermi edge, because of a lack of electrical communication between the two entities. In the present study, where BEs are referred to In-P at $128.8 \mathrm{eV}$ (avoids the possibility of differential charging), it was assumed the presence of identical charging effect between higher temperatures, i.e. $773 \mathrm{~K}$, and that at $673 \mathrm{~K}$, because of the depletion of $\mathrm{P}$ from the surface.

For these BE calculations, the unit-cell containing 156 atoms was used. For the BE calculations of $\mathrm{P}_{2} \mathrm{O}_{5}$, mp-2452 structure from materialsproject.org was used, where (1x2)x3 supercell of the unitcell containing 336 atoms in total was used. This compound is also known to show significant disorder, which needs to be taken into consideration for assessing the accuracy of theory used in this study. Overall, theoretical $\mathrm{O} 1 \mathrm{~s}$ and $\mathrm{P} 2 \mathrm{p}$ BEs are in qualitative agreement with the experiments, while In $3 \mathrm{~d}$ shows a significant systematic discrepancy, in particular, between InP and indium oxides. In our surface oxidation study, the measured BE of In $3 d$ provide information regarding the change of indium chemical environment from that of $\mathrm{InP}$ to that of oxides. Unfortunately, the error in theory appears to be very large for such a type of change in chemical environment. As such, we did not perform theoretical analysis based on In $3 \mathrm{~d}$ BE shift for surface model structures. 

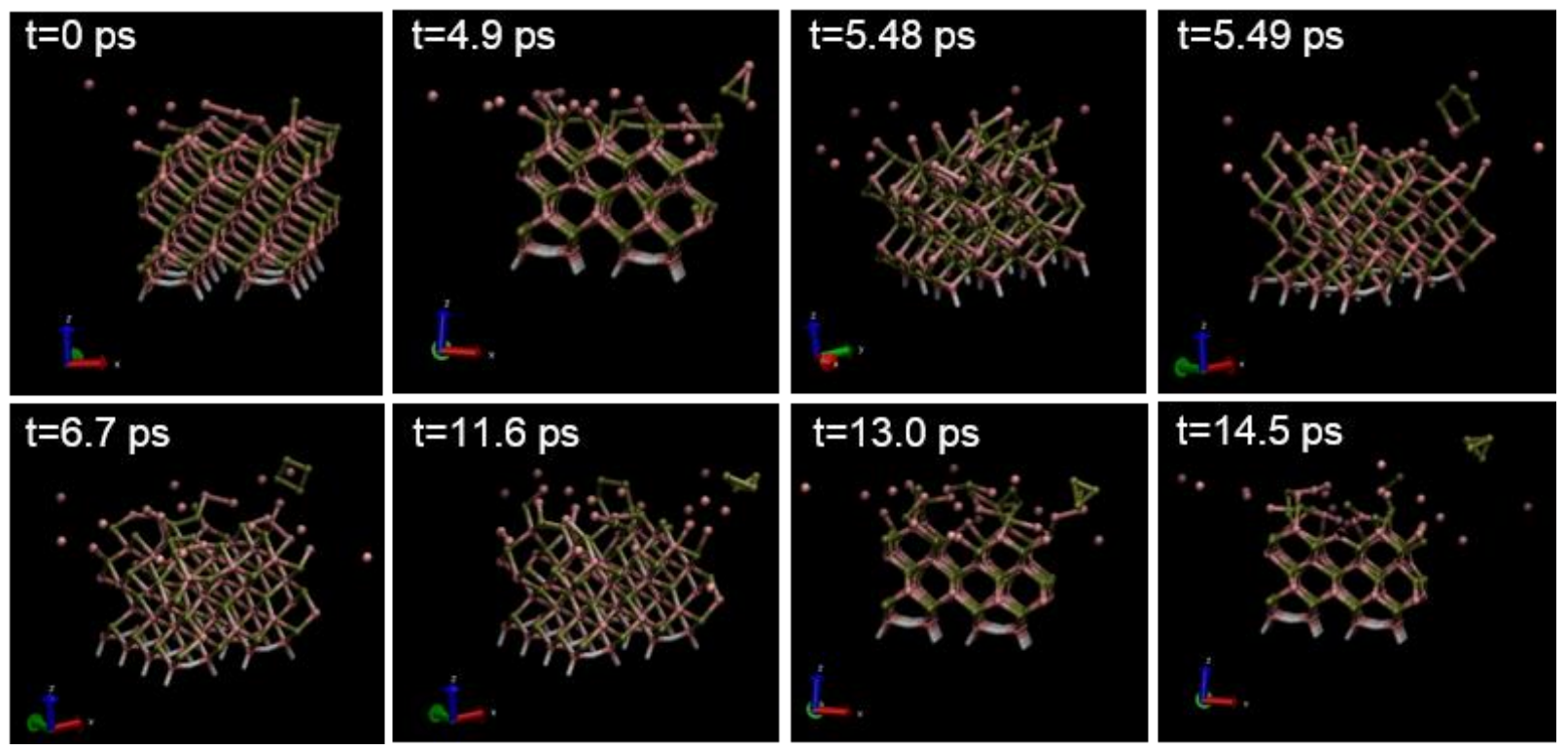

Fig. S15. Snapshots of ab-initio MD of InP(001) surface at $\mathrm{T}=1200 \mathrm{~K}$ performed with $\mathrm{dt}=1 \mathrm{fs}$. In this simulation, we used Qbox code ${ }^{37}$ combined with the ONCV pseudopotential ${ }^{38}$ and planewave expansion with $E_{c u t}=50 R y$. Here the simulation box is chosen to be a $4 x 4$ surface supercell and 9 layer thick, where the back surface is terminated with hydrogen atoms. The bottom two layers as well as the hydrogen atoms were fixed in order to avoid fictitious interaction between the surface and back surface via the level crossing (hydrogen termination of back surface is to remove the (back)surface states near the Fermi level). At about $\mathrm{t}=5.49 \mathrm{ps}$, an $\mathrm{InP}_{4}$ cluster formation is observed, which evolves into a $\mathrm{P}_{4}$ cluster with a few indium atoms interacting each other by about at 6.7 ps. Note that the $\mathrm{P}_{4}$ cluster is forming a planer structure, not the tetrahedral structure known as the stable $\mathrm{P}_{4}$ cluster structure. The planer $\mathrm{P}_{4}$ with a few In atoms stay roughly the same configuration for several ps, then, bucking of $\mathrm{P}_{4}$ (seen at about $\mathrm{t}=11.6 \mathrm{ps}$ ) eventually leads to the formation of stable tetrahedral $\mathrm{P}_{4}$ structure at about $\mathrm{t}=13$ ps followed by repulsion from the indium atoms and the surface, and ejected into vacuum by $\mathrm{t}=14.5 \mathrm{ps}$. In order to rationalize the underlying mechanism of $\mathrm{P}_{4}$ ejection, in particular, the observed the planer $\mathrm{P}_{4}$ with indium atoms as the dynamical transition state, we have calculated Maximally Localized Wannier Functions (MLWF) ${ }^{39}$ for these snapshots. The results indicated that the planer $\mathrm{P}_{4}$ is anionic meaning that the number of MLWF identified as the bonding electrons of the cluster was two more than the valence electrons of four $\mathrm{P}$ atoms, and the nearby In atoms were cationic meaning that the number of MLWF in the vicinity of In aggregate nearby the $\mathrm{P}_{4}$ was smaller than number of valence electrons of these In atoms, while the $\mathrm{P}_{4}$ cluster showed planer structure. This suggests that, the planer $\mathrm{P}_{4}$ is bound to In atoms via coulomb interaction. When the $\mathrm{P}_{4}$ cluster transforms into the tetrahedral structure, the cluster abruptly turns to neutral charge state, which leads to the ejection due to sudden loss of attractive coulomb interaction with the In cluster. 


\section{References}

(1) Sung, M. M.; Lee, S. H.; Lee, S. M.; Marton, D.; Perry, S. S.; Rabalais, J. W. Composition and Morphology of $\operatorname{InP}(100)$ Surfaces as a Function of Low Energy $\mathrm{Ar}^{+}$Bombardment and Annealing. Surf. Sci. 1997, 382, 147-153.

(2) Pham, T. A.; Zhang, X.; Wood, B. C.; Prendergast, D.; Ptasinska, S.; Ogitsu, T. Integrating Ab Initio Simulations and X-Ray Photoelectron Spectroscopy: Toward a Realistic Description of Oxidized Solid/Liquid Interfaces. J. Phys. Chem. Lett. 2018, 9, 194-203.

(3) Zhang, X.; Ptasinska, S. Distinct and Dramatic Water Dissociation on GaP(111) Tracked by Real-Time Near-Ambient Pressure X-Ray Photoelectron Spectroscopy. Phys. Chem. Chem. Phys. 2015, 17, 3909-3918.

(4) Zhang, X.; Ptasinska, S. Heterogeneous Oxygen-Containing Species Formed via Oxygen or Water Dissociative Adsorption onto a Gallium Phosphide Surface. Top. Catal. 2016, 59, 564573.

(5) Zhang, X.; Ptasinska, S. Dissociative Adsorption of Water on an $\mathrm{H}_{2} \mathrm{O} / \mathrm{GaAs}$ (100) Interface: In Situ Near-Ambient Pressure XPS Studies. J. Phys. Chem. C 2014, 118, 4259-4266.

(6) Chen, G.; Visbeck, S. B.; Law, D. C.; Hicks, R. F. Structure-Sensitive Oxidation of the Indium Phosphide (001) Surface. J. Appl. Phys. 2002, 91, 9362-9367.

(7) Streubel, P.; Peisert, H.; Hesse, R.; Chasse, T.; Szargan, R. Chemical Bonding Studies on UV/Ozone-Treated and $\left(\mathrm{NH}_{4}\right)_{2} \mathrm{~S}$-Treated InP(001) Surfaces by X-Ray PhotoelectronSpectroscopy and X-Ray-Induced Auger Electron Spectroscopy. Surf. Interf. Anal. 1995, 23, 581588.

(8) Franke, R.; Chasse, T.; Streubel, P.; Meisel, A. Auger Parameters and Relaxation Energies of Phosphorus in Solid Compounds. J. Electron Spec. Related Phenom. 1991, 56, 381-388.

(9) Hollinger, G.; Bergignat, E.; Joseph, J.; Robach, Y. On the Nature of Oxides on InP Surfaces. J. Vac. Sci. Technol. A: Vac. Surf. Films 1985, 3, 2082-2088.

(10) Kendelewicz, T.; Mahowald, P. H.; Bertness, K. A.; McCants, C. E.; Lindau, I.; Spicer, W. E. Surface Shifts in the in 4d and P 2p Core-Level Spectra of InP(110). Phys. Rev. B 1987, 36, 6543-6546.

(11) Patanen, M.; Aksela, S.; Urpelainen, S.; Kantia, T.; Heinasmaki, S.; Aksela, H. Free Atom 4f Photoelectron Spectra of Au, Pb, and Bi. J. Electron Spec. Related Phenom. 2011, 183, 59-63.

(12) Siegbahn, H.; Lundholm, M. A Method of Depressing Gaseous-Phase Electron Lines in Liquid-Phase Esca Spectra. J. Electron Spec. Related Phenom. 1982, 28, 135-138.

(13) Siegbahn, H. Electron-Spectroscopy for Chemical-Analysis of Liquids and Solutions. $J$. Phys. Chem. 1985, 89, 897-909.

(14) Axnanda, S.; Scheele, M.; Crumlin, E.; Mao, B. H.; Chang, R.; Rani, S.; Faiz, M.; Wang, S. D.; Alivisatos, A. P.; Liu, Z. Direct Work Function Measurement by Gas Phase Photoelectron Spectroscopy and its Application on PbS Nanoparticles. Nano Lett. 2013, 13, 6176-6182.

(15) Crumlin, E. J.; Bluhm, H.; Liu, Z. In Situ Investigation of Electrochemical Devices Using Ambient Pressure Photoelectron Spectroscopy. J. Electron Spec. Related Phenom. 2013, 190, 8492.

(16) Gartland, P. O.; Berge, S.; Slagsvol.Bj. Photoelectric Work Function of a Copper SingleCrystal for (100), (110), (111), and (112) Faces. Phys. Rev. Lett. 1972, 28, 738.

(17) Takeuchi, K.; Suda, A.; Ushioda, S. Local Variation of the Work Function of $\mathrm{Cu}(111)$ Surface Deduced from the Low Energy Photoemission Spectra. Surf. Sci. 2001, 489, 100-106. 
(18) Duhm, S.; Gerlach, A.; Salzmann, I.; Broker, B.; Johnson, R. L.; Schreiber, F.; Koch, N. PTCDA on $\mathrm{Au}(111), \mathrm{Ag}(111)$ and $\mathrm{Cu}(111)$ : Correlation of Interface Charge Transfer to Bonding Distance. Org. Electron. 2008, 9, 111-118.

(19) Chelvayohan, M.; Mee, C. H. B. Work Function Measurements on (110), (100) and (111) Surfaces of Silver. J. Phys. C: Solid State Phys. 1982, 15, 2305-2312.

(20) Dweydari, A. W.; Mee, C. H. B. Work Function Measurements on (100) and (110) Surfaces of Silver. Phys. Status Solidi A: Appl. Res. 1975, 27, 223-230.

(21) Otalvaro, D.; Veening, T.; Brocks, G. Self-Assembled Monolayer Induced Au(111) and $\operatorname{Ag}(111)$ Reconstructions: Work Functions and Interface Dipole Formation. J. Phys. Chem. C 2012, 116, 7826-7837.

(22) Nieuwenh.Be; Sachtler, W. M. Crystal Face Specificity of Nitrogen Adsorption on a Platinum Field-Emission Tip. Surf. Sci. 1973, 34, 317-336.

(23) Nieuwenh.Be; Meijer, D. T.; Sachtler, W. M. Adsorption of Xenon on Platinum Studied by Field-Emission Microscopy. Physica Status Solidi A: Appl. Res. 1974, 24, 115-122.

(24) Iijima, Y.; Takahashi, Y.; Matsumoto, K.; Hayashi, T.; Todoroki, N.; Wadayama, T. Oxygen Reduction Reaction Activities of Pt/Au(111) Surfaces Prepared by Molecular Beam Epitaxy. J. Electroanal. Chem. 2012, 685, 79-85.

(25) Sachtler, W. M. H.; Dorgelo, G. J. H.; Holscher, A. A. The Work Function of Gold. Surf. Sci. 1966, 5, 221-229.

(26) Andrew, P.; Ilie, A. Functionalised Silver Nanowire Structures. Pro. Int. Conf. Nanosci. Technol. 2007, 61, 36-40.

(27) Pescia, D.; Meier, F. Spin Polarized Photoemission from Gold Using Circularly PolarizedLight. Surf. Sci. 1982, 117, 302-309.

(28) Lecoeur, J.; Bellier, J. P.; Koehler, C. Comparison of Crystallographic Anisotropy Effects on Potential of Zero Charge and Electronic Work Function for Gold (111), (311), (110) and (210) Orientations. Electrochim. Acta 1990, 35, 1383-1392.

(29) Tzeng, C. T.; Lo, W. S.; Yuh, J. Y.; Chu, R. Y.; Tsuei, K. D. Photoemission, Near-Edge X-Ray Absorption Spectroscopy, and Low-Energy Electron-Diffraction Study of C60 on Au(111) Surfaces. Phys. Rev. B 2000, 61, 2263-2272.

(30) Hagen, S.; Leyssner, F.; Nandi, D.; Wolf, M.; Tegeder, P. Reversible Switching of TetraTert-Butyl-Azobenzene on a $\mathrm{Au}(111)$ Surface Induced by Light and Thermal Activation. Chem. Phys. Lett. 2007, 444, 85-90.

(31) Feurprier, Y.; Cardinaud, C.; Turban, G. X-ray Photoelectron Spectroscopy Damage Characterization of Reactively Ion Etched InP in $\mathrm{CH}_{4}-\mathrm{H}_{2}$ Plasmas. J. Vac. Sci. Technol. B 1998, $16,1823-1832$.

(32) Hu, S. Z.; Scudiero, L.; Ha, S. Electronic Effect on Oxidation of Formic Acid on Supported Pd-Cu Bimetallic Surface. Electrochim. Acta 2012, 83, 354-358.

(33) Ketteler, G.; Ogletree, D. F.; Bluhm, H.; Liu, H. J.; Hebenstreit, E. L. D.; Salmeron, M. In Situ Spectroscopic Study of the Oxidation and Reduction of Pd(111). J. Am. Chem. Soc. 2005, $127,18269-18273$.

(34) Powell, C. J.; Jablonski, A.: NIST Standard Reference Database 71: NIST Electron Inelastic Mean Free Path Database: Version 1.2; NIST: Gaithersburg, Maryland, USA, 2010.

(35) Wood, B. C.; Ogitsu, T.; Schwegler, E. Local Structural Models of Complex Oxygen-and Hydroxyl-Rich GaP/InP(001) Surfaces. J. Chem. Phys. 2012, 136, 064705-064715. 
(36) Methfessel, M.; Hennig, D.; Scheffler, M. Ab-Initio Calculations of the Initial- and FinalState Effects on the Surface Core-Level Shift of Transition Metals. Surf. Sci. 1993, 287-288, 785788.

(37) Gygi, F. Architecture of Qbox: A Scalable First-Principles Molecular Dynamics Code. IBM J. Res. Dev. 2008, 52, 137-144.

(38) Schlipf, M.; Gygi, F. Optimization Algorithm for the Generation of Oncv Pseudopotentials. Comput. Phys. Commun. 2015, 196, 36-44.

(39) Marzari, N.; Mostofi, A. A.; Yates, J. R.; Souza, I.; Vanderbilt, D. Maximally Localized Wannier Functions: Theory and Applications. Rev. Mod. Phys. 2012, 84, 57. 